\title{
New aspects of the insulin resistance syndrome: impact on haematological parameters
}

\author{
M. Barbieri ${ }^{1}$, E. Ragno ${ }^{1}$, E. Benvenuti ${ }^{2}$, G.A.Zito ${ }^{1}$, A. Corsi ${ }^{2}$, L.Ferrucci ${ }^{2}$, G.Paolisso ${ }^{1}$ \\ ${ }^{1}$ Department of Geriatric Medicine and Metabolic Diseases, University of Naples, Italy \\ ${ }^{2}$ Laboratory of Clinical Epidemiology, INRCA Geriatric department, Florence, Italy
}

\section{Abstract}

Aim/hypothesis. Previous studies have shown that insulin has an important in vitro role in the regulation of human erythropoiesis. We investigated whether in vivo hyperinsulinaemia/insulin resistance affects haematological parameters.

Methods. A total of 608 subjects between 22 and 99 years of age were enrolled in the Chianti study, an epidemiological study of factors affecting mobility in old age. The degree of insulin resistance was assessed using the homeostasis model.

Results. We found a correlation between insulin resistance and red blood cell count, $(r=0.14$ $p<0.001)$, plasma haemoglobin $(r=0.16 p<0.001)$, haematocrit $(r=0.15 p<0.001)$ and plasma iron $(r=0.1 p<0.05)$ concentrations. Red blood cell count was also associated with the other biological markers of insulin resistance syndrome. Subjects with higher insulin resistance $\left(4^{\circ}\right.$ quartile) had higher red blood cell count, plasma triglycerides and low density lipoproteins (LDL) cholesterol concentrations and lower high density lipoproteins (HDL) cholesterol concentrations then subjects at the lowest quartiles of insulin resistance. Insulin resistance and BMI were significant and independent predictors of red blood cell count even when the analysis was adjusted for age, sex, waist-to-hip ratio, plasma iron and drug intake.

Conclusion/hypothesis. Our findings provide in vivo evidence of a relation between hyperinsulinaemia/insulin resistance, the main variables of insulin resistance syndrome and erythropoiesis. Increased red blood cell count could be considered as a new aspect of the insulin resistance syndrome that could contribute to the increased risk of developing cardiovascular problems. [Diabetologia (2001) 44: 1232-1237]

Keywords Hyperinsulinaemia, insulin resistance, red blood cell count, InChianti.
The clinical association of insulin resistance (IR), hypertension, obesity, dyslipidaemia (increased VLDL and decreased HDL-cholesterol concentration in plasma), higher plasma PAI -1 concentrations and

\footnotetext{
Received: 15 March 2001 and in revised form: 10 May 2001

Corresponding author: G.Paolisso, Department of Geriatric Medicine and Metabolic Diseases, IV Divisione di Medicina Interna, Piazza Miraglia 2, 80138 Napoli, Italy; e-mail: gpaoliss @tin.it

Abbreviations: IR, Insulin resistance; RBC, red blood cell; WBC, white blood cell; WHR, waist-to-hip ratio; CFU-E, colony-forming units-erythroid; BFU-E, burst forming unitserythroid; LDL, low density lipoproteins; HDL, high density lipoproteins
}

decreased arterial distensibility, is widely known as the insulin resistance syndrome [1-3]. A strong association between the occurrence of insulin resistance syndrome and cardiovascular diseases (mainly coronary heart diseases) has been also demonstrated [1-2]. Nevertheless, hyperinsulinaemia is also in itself an independent risk factor for cardiovascular diseases [4] probably due to the capacity of insulin to directly promote the growth of vascular cells and atherosclerosis [4].

The effect of insulin on cell growth is not restricted to vascular cells but might involve other types of cells. Insulin regulates human erythropoiesis in vitro [5-9] and has been shown to stimulate the proliferation of late erythroid progenitors (CFU-E) in culture of mu- 
rine fetal liver and promote growth in both human bone marrow and circulating erythroid progenitor cells [6-9].

Our data let indicate that hyperinsulinaemia/insulin resistance could stimulate erythroid progenitors proliferation and so result in an increase of $\mathrm{RBC}$ (red blood cell) mass. Because RBC mass is a risk factor for cardiovascular diseases [10], such a mechanism could explain, at least in part, the high risk of cardiovascular diseases in patients with hyperinsulinaemia/insulin resistance.

\section{Subjects and methods}

Subjects. This study is part of the InCHIANTI Study, a prospective population-based study of older people, designed by the laboratory of Clinical Epidemiology of the Italian National Research Council of Aging, (INRCA, Florence, Italy) and carried out in the Chianti geographic area (Tuscany, Italy). This database includes data from 1440 participants (between 20 and 102 years of age) randomly selected from the residents in the two municipalities of Greve in Chianti and Bagno a Ripoli using a multistage stratified sampling method [11]. Data collection started in September 1998 and was completed in March 2000.

Our study population consisted of 600 subjects between 22 and 99 years of age, selected from the cohort from Greve in Chianti, excluding those affected by diabetes mellitus and prevalent clinical cardiovascular and haematological diseases. Diabetes mellitus was diagnosed according to the criteria of the American Diabetes Association [12]. Patients with prevalent clinical cardiovascular diseases were excluded to avoid interference on the degree of IR within, and among, each group.

Subjects were asked whether they had received any medical care during the past 5 years and, if so, the reason and speciality. The names of the drugs and dosages prescribed were also recorded. Subjects taking drugs known to interfere with glucose (i.e. sulphonylureas, biguanides, insulin) or erythrocytes (i.e. cytostatics, erythropoietin) metabolism were also excluded from the study.

All subjects gave their informed consent before participating in the study which was approved by the ethical committee of our institutions.

Anthropometric determinations. Weight and height were measured using standard techniques. BMI was calculated as weight $(\mathrm{kg})$ divided by height $(\mathrm{cm})$ squared. The waist circumference was measured at the midpoint between the lower rib margin and the iliac crest (normally umbilical level) and hip circumference at the level of trochanter. Both were measured to the nearest $0.5 \mathrm{~cm}$ with a plastic tape measure and the waist-tohip ratio (WHR) was calculated.

Metabolic and cardiovascular determinations. Serum glucose and insulin were on a blood sample collected in the morning after the participants had been fasting for at least $8 \mathrm{~h}$.

Using this data, the degree of insulin resistance was calculated according to the homeostasis model assessment (HOMA) which is a good index for assessing insulin resistance in subjects with different degree of insulin resistance and has a good correlation with insulin mediated glucose uptake calculated by euglycaemic hyperinsulinaemic glucose clamp [13-14].
According to the homeostasis model assessment (HOMA) [13-14], insulin resistance (IR) was calculated as follows: $\mathrm{IR}=\mathrm{FI} \cdot \mathrm{g} / 22.5 ;$ where $\mathrm{FI}=$ fasting insulin $(\mu \mathrm{u} / \mathrm{ml})$ and $\mathrm{g}=$ fasting glucose $(\mathrm{mmol} / \mathrm{l})$.

Baseline blood pressure was recorded by standard mercury sphygmomanometer. The disappearance of sound (phase V) was used for diastolic reading. All measurements were made with the subject in supine position, on three occasions separated by intervals of $2 \mathrm{~min}$.; the mean value of the last two recorded measurements was considered for the analysis.

Analytical methods. Blood samples for insulin assay were collected in EDTA tubes and the plasma samples on the same day of collection was aliquoted in Eppendorf vials and stored at $-80^{\circ} \mathrm{C}$ until thawed for insulin assay. Plasma insulin was measured by a commercial double-antibody, solid phase radioimmunoassay (Sorin Biomedica, Milan Italy, intra-assay c.v. $3.1+0.3 \%)$.

Serum glucose, serum lipid, serum lipoprotein, plasma iron and plasma fibrinogen were measured from fresh samples drawn after an overnight fast. The serum glucose concentration was measured by an enzymatic colorimetric assay using a modified glucose oxidase-peroxidase method (Roche Diagnostics, Mannheim, Germany) and a Roche-Hitachi 917 analyser.

Commercial enzymatic tests were used for determining serum total- and HDL cholesterol and triglyceride (Roche Diagnostics) concentrations. Serum LDL cholesterol concentrations were calculated by the Friedewald formula [15]. The interassay coefficient of variation was less than $3.8 \%$ for total cholesterol, less $5.0 \%$ for HDL cholesterol, less than $2.5 \%$ for triglycerides.

Red blood cell count, white blood cells, platelets, haemoglobin concentration and hematocrit were done using a haematology autoanalyzer (SE 9000 DASIT). Serum iron concentration was determined by a colorimetric assay (Roche Diagnostics, Mannheim Germany) and a Roche-Hitachi 917 analyser.

Blood samples for fibrinogen test were collected in citrated tubes and the plasma fibrinogen concentrations were measured according to Clauss (STA Fibrinogen kit, Diagnostica Stago Roche Diagnostics) and a Sta Stago Boehringer Mannheim analyser.

Calculation and statistical analysis. To approximate normal distributions log-transformed values for plasma triglycerides, insulin and IR (HOMA) were used in the analysis. Pearson Product-moment correlations were calculated to test associations among variables. Impact of age on RBC, BMI, triglycerides, LDL cholesterol, haemoglobin and hematocrit was assessed by analysis of covariance (ANCOVA). To investigate the relation between red blood cell count, anthropometric and metabolic characteristics, data were stratified in quartiles of insulin resistance degree. ANOVA was used for calculating the $p$ value for the trend for each variable among the different quartiles.

A cluster analysis showed whether an overall variable obtained by clustering variables of the insulin resistance syndrome was associated with RBC count. For this purpose, we created a compound score referred to as a clustering score, as the sum of Z-scores of the main variable of IR, BMI, triglycerides, LDL-cholesterol and HDL- cholesterol. A z-score indicates the position of an individual value of a variable in the total distribution of the variable in the population and is calculated as follows: (individual value - mean value) over standard deviation. The association between this variable and red blood cell count was studied using linear regression. 
Table 1. Clinical characteristics of study group $(n=600)$

\begin{tabular}{lc}
\hline Age $($ years $)$ & $67 \pm 16$ \\
Glucose $(\mathrm{mmol} / \mathrm{l})$ & $4.8 \pm 0.6$ \\
Plasma insulin $(\mathrm{pmol} / \mathrm{l})$ & $89.6 \pm 41.6$ \\
BMI $(\mathrm{kg} / \mathrm{m} 2)$ & $26.7 \pm 4.1$ \\
WHR & $0.89 \pm 0.09$ \\
Triglycerides $(\mathrm{mmol} / \mathrm{l})$ & $1.3 \pm 0.7$ \\
Total cholesterol $(\mathrm{mmol} / \mathrm{l})$ & $5.4 \pm 1.0$ \\
LDL-cholesterol $(\mathrm{mmol} / \mathrm{l})$ & $3.5 \pm 0.9$ \\
HDL-cholesterol $(\mathrm{mmol} / \mathrm{l})$ & $1.4 \pm 0.3$ \\
RBC $\cdot 106 / \mathrm{ml}$ & $4.51 \pm 0.44$ \\
WBC $\cdot 103 / \mathrm{ml}$ & $6.1 \pm 1.5$ \\
Platelet $\cdot 103 / \mathrm{ml}$ & $228 \pm 64$ \\
Haemoglobin $(\mathrm{g} / \mathrm{dl})$ & $13.7 \pm 1.4$ \\
Hematocrit $(\%)$ & $40.8 \pm 3.7$ \\
Fibrinogen $(\mathrm{mg} / \mathrm{dl})$ & $356 \pm 80$ \\
Plasma iron $(\mathrm{mmol} / \mathrm{l})$ & $14.3 \pm 4.4$ \\
SBP $(\mathrm{mmHg})$ & $146 \pm 23$ \\
IR(HOMA) & $2.7 \pm 1.4$ \\
Smokers/non-smokers & $249 \pm 351^{\mathrm{a}}$
\end{tabular}

SBP systolic blood pressure. All values are means \pm SEM

${ }^{\text {a }}$ Chi-Square $\left(\chi^{2}\right)$ test: $p<0.01$ smokers vs non-smokers

Multivariate linear regression analysis was used to test the independent association of age, sex, BMI, WHR, plasma iron, drug intake, smoking habits and IR (HOMA) with red blood cell count.

Statistical analyses were done using an SPSS software package (Chicago, Ill., USA). All values are presented as Means \pm SEM. A $p$ value of less than 0.05 was considered to be statistically significant.

\section{Results}

The clinical characteristics of the study group are indicated in Table 1 . Subjects were old, slightly overweight with a mainly central body fat distribution.

In the whole group $(n=600)$, IR was positively correlated with BMI $(r=0.39 p<0.001)$, plasma concentrations of triglycerides $(r=0.30 p<0.001)$ and LDL-cholesterol $(r=0.14 p<0.001)$ concentrations, and negatively correlated with concentrations of HDL-cholesterol $(r=-0.12 p<0.005)$. A positive correlation between insulin, IR and the main haematological variables implicated in erythropoiesis was also found. In particular, insulin correlated with RBC $(r=0.11 p<0.01)$ (Fig. 1), plasma haemoglobin $(r=0.12 \quad p<0.003) \quad$ concentrations, hematocrit $(r=0.15 p<0.001)$ value and plasma iron $(r=0.11$ $p<0.01)$ concentrations. Furthermore, IR correlated with $\mathrm{RBC}(r=0.14 p<0.001)$ (Fig. 1$)$, plasma haemoglobin $(r=0.16 p<0.001)$ concentrations, hematocrit $(r=0.15 p<0.001)$ value and plasma iron $(r=0.1$ $p<0.05)$ concentrations. All these associations were still significant $(p<0.05)$ after adjustment for age (data not shown). IR was not associated with the number of white blood cells (WBC) $(r=0.01$; $p=0.8)$ or platelet $(r=-0.07 ; p=0.06)$.
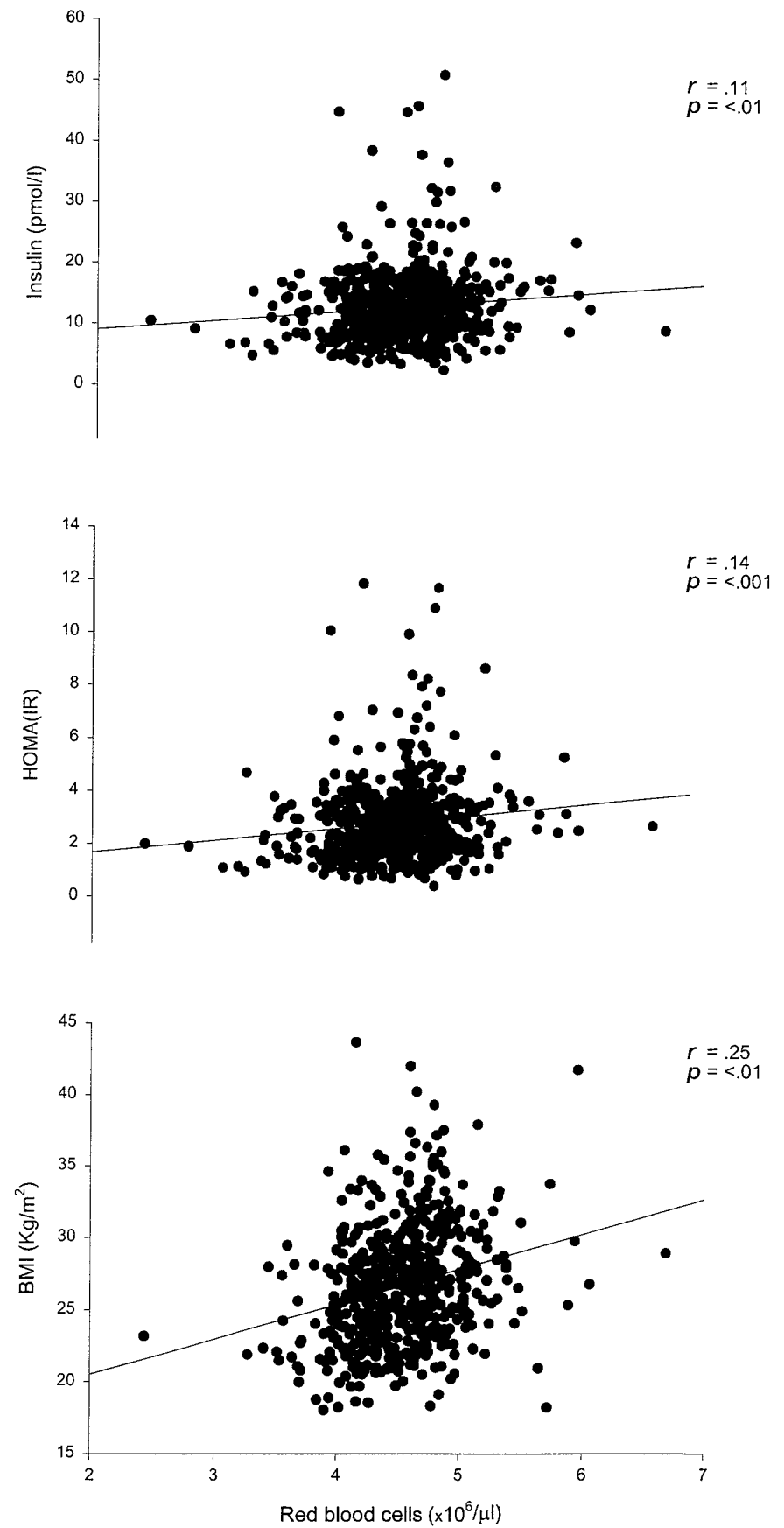

Fig. 1. Correlation analyses between BMI $(r=25, p=<0.01)$, plasma insulin $(r=1.4, p=<0.001)$, IR $(r=11, p=<0.01)$ and red blood cell count

Finally, a significant association of RBC count with the other main variables of insulin resistance syndrome was also found (Fig. 1 and Table 2).

Stratifying metabolic and anthropometric data for degree of IR, subjects with a higher degree of IR ( $4^{\circ}$ quartile) had a higher RBC count, plasma triglycerides and LDL cholesterol concentrations and lower HDL cholesterol concentrations than subjects at the lowest quartiles of IR (Table 3). Furthermore, the clustering analysis score of insulin resistance vari- 
Table 2. Correlations between red blood cell count and anthropometric and metabolic parameters

\begin{tabular}{llcl}
\hline & $n$ & $\begin{array}{l}\text { Red blood } \\
\text { cell count }\end{array}$ & $p$ \\
\hline Age & 600 & -0.16 & $<.001$ \\
Insulin $^{\mathrm{a}}$ & 593 & 0.11 & $<.01$ \\
IR (HOMA) $^{\mathrm{a}}$ & 593 & 0.14 & $<.001$ \\
BMI & 559 & 0.24 & $<.001$ \\
WHR & 561 & 0.05 & $\mathrm{NS}$ \\
Triglycerides & 600 & 0.12 & $<.005$ \\
HDL-cholesterol $^{\mathrm{a}}$ & 600 & -0.11 & $<.008$ \\
LDL-cholesterol $_{\text {Haemoglobin }}$ & 600 & 0.06 & $\mathrm{NS}$ \\
Fibrinogen & 600 & 0.79 & $<.001$ \\
Plasma iron & 598 & -0.15 & $<.001$ \\
\hline
\end{tabular}

NS Not significant

${ }^{a}$ Back log transformed

ables was positively associated with RBC count $(r=0.16 p<.001)$. Among the different groups no changes in plasma $\mathrm{WBC}$ and platelet counts were found ( $p=0.218)$.

As far as smoking habit is concerned, a prevalence of non-smokers was found (Table 1). Furthermore, categorizing subjects in smokers and non-smokers, smoking subjects had a higher RBC count than nonsmokers $\left(4.60 \pm 0.42 \times 10^{6} / \mu \mathrm{L}\right.$ vs $4.45 \pm 0.44 \times 10^{6} /$ $\mu \mathrm{L} ; p<0.01$ ), indeed, no difference in HOMA index between smokers and no smokers $(2.72 \pm 1.5$ vs $2.80 \pm 1.4 ; p=0.47$ ) was found. Furthermore, subjects with a higher degree of IR ( $4^{\circ}$ quartile) were mainly non-smokers (Table 3).

A multivariate linear regression analyses with RBC count as a dependent variable and with a model made by age, sex, WHR, plasma iron, drugs intake and smoking habits showed that IR and BMI were predictors of RBC count when enclosed separately. In contrast, the same analysis including both BMI and IR showed that only BMI, age and sex had a significant association with RBC count (Table 4).

\section{Discussion}

Our study provides evidence that hyperinsulinaemia/ insulin resistance is associated with increased RBC mass.

Various cytokines and growth factors regulate the development of mature RBC. Among such factors, erythropoietin is required for survival and differentiation of the erythropoietic progenitors [16]. Other growth factors including insulin have a synergistic effect together with erythropoietin on stimulating the proliferation of the erythroid colonies [17-19]. The role of insulin in the regulation of human erythropoiesis has been widely documented in vitro [5-9]. In fact, previous studies found that physiological concentrations of insulin directly stimulates the proliferation of late erythroid progenitors (CFU-E) in a culture of murine fetal liver [7] and promote growth in both human bone marrow and circulating erythroid progenitor cells in vitro [6-9]. The mechanism of the stimulatory effects of human insulin on human bone marrow CFU-E and BFU-E (burst forming unitserythroid) and the relation between insulin and erythropoietin have been previously investigated $[8-9,20]$. Briefly, the insulin receptor itself is thought to be involved in RBC proliferation and the insulin receptor (INS-R) has been detected on human erythropoietic cells at different stages of development, suggesting that human insulin acts at all stages of erythropoiesis [8]. Using a serum free system, it has

Table 3. Quartiles of insulin resistance

\begin{tabular}{|c|c|c|c|c|c|}
\hline & $\begin{array}{l}\text { 1st quartile } \\
(n=145) \\
(<1.86)\end{array}$ & $\begin{array}{l}\text { 2nd quartile } \\
(n=154) \\
(1.86-2.67)\end{array}$ & $\begin{array}{l}\text { 3rd quartile } \\
(n=138) \\
(2.67-3.52)\end{array}$ & $\begin{array}{l}\text { 4th quartile } \\
(n=163) \\
(>3.52)\end{array}$ & $p$ for trend \\
\hline IR (HOMA) & $1.3 \pm 0.3$ & $2.13 \pm 0.19$ & $2.9 \pm 0.23$ & $4.47 \pm 1.58$ & $<.001$ \\
\hline $\mathrm{BMI}^{\mathrm{a}}$ & $24 \pm 2.9$ & $26 \pm 3.3$ & $27 \pm 4.5$ & $28 \pm 4.2$ & $<.001$ \\
\hline WHR & $0.89 \pm 0.08$ & $0.89 \pm 0.1$ & $0.89 \pm 0.07$ & $0.90 \pm 00: 08$ & NS \\
\hline Triglycerides $(\mathrm{mmol} / \mathrm{l})^{\mathrm{a}}$ & $1.17 \pm 0.48$ & $1.24 \pm 0.49$ & $1.36 \pm 0.77$ & $1.65 \pm 0.93$ & $<.001$ \\
\hline $\mathrm{RBC} \cdot 106 / \mathrm{ml}^{\mathrm{a}}$ & $4.39 \pm 0.41$ & $4.47 \pm 0.45$ & $4.59 \pm 0.43$ & $4.60 \pm 00: 41$ & $<.001$ \\
\hline $\mathrm{WBC} \cdot 103 / \mathrm{ml}$ & $6.12 \pm 1.4$ & $6.17 \pm 1.4$ & $5.99 \pm 1.5$ & $6.36 \pm 1.7$ & NS \\
\hline Platelet $\cdot 103 / \mathrm{ml}$ & $228 \pm 57$ & $237 \pm 72$ & $224 \pm 55$ & $221 \pm 00: 00$ & NS \\
\hline Haemoglobin $(\mathrm{g} / \mathrm{dl})^{\mathrm{a}}$ & $13.3 \pm 1.5$ & $13.6 \pm 1.5$ & $13.9 \pm 1.2$ & $14.0 \pm 1.3$ & $<.001$ \\
\hline Hematocrit $(\%)^{\mathrm{a}}$ & $39.7 \pm 3.8$ & $40.6 \pm 4.0$ & $41.4 \pm 3.2$ & $41.3 \pm 3.4$ & $<.005$ \\
\hline Fibrinogen (mg/dl) & $349 \pm 78$ & $358 \pm 78.5$ & $349 \pm 81$ & $364 \pm 78$ & NS \\
\hline
\end{tabular}

All values are Means \pm SEM; SBP, systolic blood pressure, NS, not significant

${ }^{\text {a }}$ Adjusted for age

${ }^{\mathrm{b}}$ Chi-Square $\left(\chi^{2}\right)$ test: $p<0.05$ smokers vs no smokers 
Table 4. Linear multiple regression analyses with red blood cell count as dependent variable $(n=600)$

\begin{tabular}{|c|c|c|c|c|}
\hline Variable & $\beta$ & $\mathrm{t}$ & $p$ & \\
\hline Age & -0.13 & -3.28 & $<.001$ & $\mathrm{R}^{2}=0.21$ \\
\hline Sex & -0.33 & -7.04 & $<.001$ & \\
\hline WHR & 0.01 & 0.32 & .747 & \\
\hline BMI & 0.28 & 7.25 & $<.001$ & \\
\hline Plasma iron & 0.08 & 2.12 & $<.05$ & \\
\hline Drug intake & -0.02 & -0.49 & .619 & \\
\hline Smoking & 0.007 & $00: 15$ & .879 & \\
\hline Age & -0.13 & -3.49 & $<.001$ & $\mathrm{R}^{2}=0.18$ \\
\hline Sex & -0.33 & -7.28 & $<.001$ & \\
\hline WHR & -0.007 & 0.18 & .856 & \\
\hline Plasma iron & 0.11 & 2.87 & $<.005$ & \\
\hline IR (HOMA) $)^{a}$ & 0.18 & 4.66 & $<.001$ & \\
\hline Drug intake & -0.01 & -0.36 & .719 & \\
\hline Smoking & -0.02 & -0.43 & .663 & \\
\hline Age & -0.12 & -3.13 & $<.001$ & $\mathrm{R}^{2}=0.22$ \\
\hline Sex & -0.34 & -7.23 & $<.001$ & \\
\hline WHR & -0.01 & 0.24 & .809 & \\
\hline BMI & 0.27 & 6.24 & $<.001$ & \\
\hline Plasma iron & 0.08 & 2.18 & $<.05$ & \\
\hline IR (HOMA) $)^{\mathrm{a}}$ & 0.05 & 1.27 & $<.201$ & \\
\hline Drug intake & -0.02 & -0.51 & .610 & \\
\hline Smoking & -0.002 & 0.03 & .973 & \\
\hline
\end{tabular}

a Back log transformed

been shown [20] that insulin needs to bind with its own receptor before stimulating the erythroid progenitors, suggesting a direct action of this hormone on CFU-E and BFU-E.

The most widely accepted theory explaining how insulin affects erythropoiesis is that activation of tyrosine kinase in the insulin receptor could be essential for the growth-promoting action of insulin [21-22]. Indeed, previous studies show that stimulation of insulin and erythropoietin receptors induces phosphorylation of a similar, although not identical, set of intracellular proteins with the activation of different signal transduction pathways [23-27].

The in vivo relation between insulin and RBC count has been poorly documented. Indirect evidence comes from the data [28] showing that polycythaemia is often observed in newborn babies of diabetic mothers, probably because of the stimulatory effect of insulin on cord blood erythroid progenitors. Our study provides in vivo evidences of a relationship between hyperinsulinaemia/insulin resistance and RBC. Interestingly, a strong correlation between haematological parameters and the main variables of IR syndrome were also found, indicating that the increased RBC mass is a new additional feature of the IR syndrome. This is important because high RBC count is a strong independent predictor of acute cardiovascular events such as stroke and myocardial infarction [10].

Because our findings were obtained from crosssectional data, the cause and effect relation is not clear. Nevertheless, some of the findings of our analysis support the hypothesis. Firstly, stratifying meta- bolic and anthropometric data for degree of IR, subjects with a higher degree of IR ( $4^{\circ}$ quartile) had a higher red blood cell count, plasma triglycerides and LDL cholesterol concentrations and lower HDL cholesterol concentrations than subjects at the lowest quartiles of IR. Furthermore, in multivariate analysis IR was significantly associated with red blood cell count independently of age, sex, WHR, plasma iron, drug intake and smoking habits. Not surprisingly, this model explained only $18 \%$ of variance because - even though CFU-E requires insulin for erythroid development [18] - insulin activity is synergistic with, but not alternative to, the effect of erythropoietin on growth of erithroid progenitors [8, 20, 29]. Indeed, although insulin should be considered a co-factor of erythropoietin, it had no effect on erythropoiesis in the absence of erythropoietin $[8,20]$.

In our analysis, only BMI had a significant association with RBC count when both BMI and IR were enclosed in the same model. Such a result could be due to BMI rather than the degree of IR in the modulation of RBC count. Nevertheless, BMI is a strong predictor determinant of IR and it is therefore probable that the statistical relation occurring between the two variables (BMI and IR) results in the strongest one (BMI) weakening the effect or weight of the other (IR).

A potential impact of the smokers to non-smokers ratio on the effect of IR on RBC count cannot be ruled out. Our results did not, however, show a difference in the HOMA index between smokers and nonsmokers $(p=\mathrm{NS})$ even though smokers had a higher RBC count than non-smokers $(p<0.01)$. Furthermore, subjects with a higher degree of IR (4th quartile) were mainly non-smokers (Table 3 ). Finally, a multivariate linear regression analyses with an RBC count as a dependent variable showed that IR was a significant and independent predictor of RBC count even when the analysis was adjusted for smoking habits (Table 4). Furthermore, in this analysis no significant association between smoking habit and RBC count was found.

Our study suggests that insulin might have a role in the treatment of haematological disorders due to erythropoietin resistance or inadequate erythropoietin concentrations. This hypothesis seems supported by in vitro results showing that human insulin has a stimulatory effect on erythroid progenitors independently of plasma erythropoietin concentrations [8]. Of note, the effect on haematological parameters will have to be weighed against the hypoglycaemic effect of insulin.

In conclusion, our study provides in vivo evidence of a relation between hyperinsulinaemia/insulin resistance, the main variables of IR syndrome, and haematological parameters thus suggesting an increased RBC count as a new aspect of the IR syndrome. 
Because the RBC count and mass greatly affect the rheologic properties of blood which, in turn, are strong independent predictors of major cardiovascular acute events [10], the effect of hyperinsulinaemia on RBC could help explain the high rates of cardiovascular events that have been found in patients with the IR syndrome.

\section{References}

1. De Fronzo RA, Ferrannini E (1991) Insulin resistance. A multifaceted syndrome responsible for NIDDM, obesity, hypertension, dyslipidemia, and atherosclerotic cardiovascular diseases. Diabetes Care 14: 173-194

2. Reaven GM (1988) Banting lecture 1988. Role of insulin resistance in human disease. Diabetes 37: 1597-1606

3. Van Popele NM, Westendorp ICD, Bots ML et al. (2000) Variables of the insulin resistance syndrome are associated with reduced arterial distensibility in healthy non-diabetic middle aged women. Diabetologia 43: 665-672

4. Despres JP, Lamarche B, Mauriege P et al. (1996) Hyperinsulinaemia as an independent risk factor for ischemic hearth diseases. N Engl J Med 334: 952-957

5. Golde DW (1980) In vitro effects of growth hormone. In: Pecile A, Muller EE, (eds) Growth hormone and biologically active peptides. Excerpta Medica, Amsterdam, pp 52-66

6. Bersch N, Groopman JE, Golde DW (1982) Natural and biosynthetic insulin stimulates the growth of human erythroid progenitors in vitro. J Clin Endocrinol Metab 55: 1209-1211

7. Kurtz A., Selkmann W, Bauer C (1983) Insulin stimulates erythroid colony formation independently of erythropoietin. Br J Haematol 53: 311-316

8. Aoki I, Taniyama M, Toyama K, Homori M, Ishikawa K (1994) Stimulatory effect of human insulin on erythroid progenitors (CFU-E and BFU-E) in human CD34 separated bone marrow cells and the relationship between insulin and erythropoietin. Stem Cells 12: 329-338

9. Ratajczak J, Zhang Q, Pertusini E, Wojczyk BS, Wasik MA, Ratajczak MZ (1998) The role of insulin (INS) and insulin like growth factor-1 (IGF-1) in regulating human erythropoiesis. Studies in vitro under serum free conditions - comparison to other cytokines and growth factors. Leukemia 12: 371-381

10. Lowe GD (1992) Blood viscosity and cardiovascular disease. Thromb Haemost 6: $494-498$

11. Ferrucci L, Bandinelli S, Benvenuti E et al. (2000) Subsystems contributing to the decline in ability to walk: bridging the gap between epidemiology and geriatric practice in the Inchianti study. J Am Geriatr Soc 48: 1618-1625

12. Alberti KGMM, Zimmet PZ for the WHO Consultation (1998) Definition, diagnosis and classification of diabetes mellitus and its complications. Part 1: diagnosis and classification of diabetes mellitus. Provisional report of a WHO consultation. Diabet Med 15: 539-553

13. Matthews DR, Hosker JP, Rudenski AS, Naylor BA, Treacher DF, Turner RC (1985) Homeostasis model assessment: insulin resistance and beta-cell function from fasting plasma glucose and insulin concentrations in man. Diabetologia 28: 412-419
14. Bonora E, Targher G, Alberiche M et al. (2000) Homeostasis model assessment closely mirrors the glucose clamp technique in the assessment of insulin sensitivity. Studies in subjects with various degrees of glucose tolerance and insulin sensitivity. Diabetes Care 23: 57-63

15. Friedewald WT, Levy R, Fredricson DS (1972) Estimation of serum low density lipoprotein without the use of a preparative ultracentrifuge. Clin Chem 18: 499-502

16. Wu H, Klingmueller U, Acurio U, Hsiao JG, Lodish HF (1997) Functional interaction of erythropoietin and stem cell factor receptors is essential for erythroid colony formation. Proc Natl Acad Sci USA 94: 1806-1810

17. Akahane K, Tojo A, Urabe A, Takaku F (1987) Pure erythropoietic colony and burst formations in serum-free culture and their enhancement by insulin like growth factor 1. Exp Hematol 15: 797-802

18. Boyer SH, Bishop TR, Rogers OC, Noyes AN, Frelin LP, Hobbs S (1992) Roles of erythropoietin, insulin-like growth factor 1, and unidentified serum factors in promoting maturation of purified murine erythroid colony-forming units. Blood 80: 2503-2512

19. Ratajczak MZ, Light B, Ratajczak J, Kuczynski W, Gewirtz AM (1993) Human erythropoiesis in vitro: definition, and clinical implications, of 'optimal' stimulatory conditions. Cancer Res Ther Cont 94: 1806-1810

20. Sawada K, Krantz SB, Dessypris EN, Koury ST, Sawyer ST (1989) Human colony-forming units erythroid do not require accessory cells but do require direct interaction with insulin like growth factor 1 and/or insulin for erythroid development. J Clin Iinvest 83: 1701-1709

21. Grigorescu F, White MF, Karn CR (1983) Insulin binding and insulin dependent phosphorylation of the insulin receptor solubilized from human erythrocytes. J Biol Chem 258: $13708-13716$

22. Wang LM, Myers MG, Sun KJ, Aaronson SA, White M, Pierce JH (1993) IRS-1: Essential for insulin and IL-4 stimulated mitogenesis in hematopoietic cells. Science 261: 1591-1594

23. Carroll MP, Spivax JL, McMahon M, Weich N, Rapp UR, May WS (1991) Erythropoietin induce Raf-1 activation and Raf- 1 is required for erythropoietin mediated proliferation. J Biol Chem 23: 14964-14969

24. Sun XJ, Wang LM, Zhang Y et al. (1995) Role of IRS-2 in insulin and cytokine signaling. Nature 377: 173-177

25. Verdier F, Chretien S, Billat C, Gisselbrecht S, Lacombe C, Mayeux P (1997) Erythropoietin induces the tyrosine phosphorilation of insulin receptor substrate-2. J Biol Chem 42: 26173-26178

26. Wickrema A, Shahab U, Sharma A et al. (1999) Engagement of Gab 1 and Gab2 in Erythropoietin signaling. J Biol Chem 274: 24469-24474

27. Lecoq-Lafon C, Verdier F, Fichelson S et al. (1999) Erythropoietin induces the tyrosine phosphorilation of Gab1 and its association with SHC, SHP2, SHIP, and Phosphatidylinositol 3-kinase. Blood 8: 2578-2585

28. Perrine SP, Greene MF, Lee PDK, Cohen RA, Faller DV (1986) Insulin stimulate cord blood erythroid progenitor growth: evidence for an etiological role in neonatal polycythaemia. Bri J Haematol 64: 503-511

29. Dainiak N, Kreczko S (1985) Interaction of insulin, insulin like growth factor II and platelet- derived growth factor in erythropoietic culture. J Clin Invest 76: 1237-1242 